\title{
La crítica de Celms al Solipsismo de Husserl: Un debate fenomenológico en el contexto de Letonia*
}

\section{Celms' Critique of Husserl's Solipsism: a Pheno- menological Debate in the Latvian Context}

\author{
OLAYA FERNÁNDEZ GUERRERO \\ UNED La Rioja
}

Recibido: 21/10/2015 Aceptado:17/11/2015

\section{RESUMEN}

Este trabajo hace una breve introducción al pensamiento del filósofo letón Teodors Celms, que fue alumno de Husserl y que planteó tempranamente algunas interesantes críticas a la fenomenología. En concreto, Celms se interesó por el problema de la intersubjetividad, pues cree que el método fenomenológico deriva en un solipsismo que dificulta el acceso al conocimiento de otras conciencias. Este estudio presenta la crítica de Celms y la respuesta de Husserl al problema planteado por su alumno letón.

PALABRAS CLAVE

CELMS, FENOMENOLOGÍA, HUSSERL, INTERSUBJETIVIDAD, SOLIPSISMO

\section{ABSTRACT}

This paper provides a brief introduction to the ideas of Latvian philosopher Teodors Celms, who was one of Husserl's students and raised some interesting early criticism on phenomenology.

* Esta nota recoge parte de los resultados de una investigación desarrollada en el Instituto de Filosofía y Sociología de la Latvijas Universitate, Riga (Letonia) en el otoño de 2015, y financiada con una beca posdoctoral del Gobierno de Letonia. 
Specifically, Celms was interested on the problem of intersubjectivity, as he considered that the phenomenological method results in a solipsism which hinders access to knowledge of other consciousness. This paper presents Celms' critique and Husserl's answer to the issue posed by his Latvian pupil.

\section{KEYWORDS}

CELMS, PHENOMENOLOGY, HUSSERL, INTERSUBJETIVITY, SOLIPSISM

\section{INTRODUCCIÓN: CeLMS Y LA FENOMENOLOGÍA EN LETONIA}

DURANTE LAS PRIMERAS DÉCADAS DEL SIGLO XX, pensadores de distintos países europeos viajaron a Alemania para completar su formación académica junto a Edmund Husserl, atraídos por los novedosos planteamientos de su filosofía fenomenológica. Heidegger, Sartre, Carnap o Patocka fueron sus seguidores más renombrados, pero la lista es mucho más extensa. Uno de esos discípulos fue Teodors Celms, nacido en Letonia en 1893 y formado primero en Moscú y posteriormente en Friburgo, donde fue alumno de Husserl. Entre 1927 y 1944, Celms regresó a Riga y ocupó la cátedra de filosofía en la Universidad de Letonia, desde donde impulsó los estudios fenomenológicos dando lugar a una amplia corriente de investigaciones académicas en este campo que continúa hasta hoy. La ocupación de Letonia por parte del ejército ruso, en la década de 1940, provocó la huida de toda una generación de intelectuales, incluido Celms, quien residió algún tiempo en Alemania y luego emigró a Estados Unidos, donde vivió varias décadas trabajando como profesor de filosofía en enseñanza secundaria, y donde fallecería en 1989.

Tras la contienda bélica, Letonia se incorporó a la Unión Soviética y a partir de ese momento toda la producción académica se orientó hacia la filosofía marxista-leninista, por lo que en los siguientes años la fenomenología apenas tuvo cabida en el contexto universitario báltico. A finales de los 60 surge una generación de investigadores e investigadoras que recupera el interés por la fenomenología, aunque el auge definitivo de esta línea filosófica no llegará hasta 1990, cuando Letonia se convierte en un Estado independiente y reorganiza su espacio académico de manera autónoma. Las profesoras Maija Kule y Anna-Teresa Tymieniecka han sido responsables en gran medida de ese nuevo auge de la fenomenología en el ámbito letón, y en torno a ellas se ha creado una notable comunidad docente e investigadora centrada en esa corriente de pensamiento, con una destacada producción filosófica y una intensa actividad divulgativa. ${ }^{1}$

1 Para una panorámica más amplia de los estudios fenomenológicos en Letonia, ver E. Buceniece, «Teodors Celms, Kurt Stavenhagen and Phenomenology in Latvia», Analecta Husserliana, 80 (2003) pp. 312-316. 


\section{LA CRÍTiCA DE Celms Al SOlipsismo de Husserl}

La principal aportación de Teodors Celms al criticismo husserliano es su obra Der phänomenologische Idealismus Husserls, escrita y publicada en alemán en 1928 y traducida al español por José Gaos -el mismo que traduce a Heidegger- en 1931. ${ }^{2}$ En el momento en que Celms escribe su texto, Husserl había publicado ya sus Investigaciones lógicas, La filosofía como ciencia estricta e Ideas I, por lo que las reflexiones de Celms sobre el alcance y las limitaciones del método fenomenológico expuesto por su maestro se centran en esos tres trabajos, y también en algunos manuscritos más breves a los que tuvo acceso durante su época de estudiante bajo la tutela de Husserl. En cualquier caso, Celms se muestra cercano a esa corriente de pensamiento, e insiste en el valor de las enseñanzas de Brentano y Husserl acerca de la estructura intencional de la conciencia: «La tesis de que la intencionalidad es un carácter de lo psíquico, que puede aprehenderse descriptivamente, es un descubrimiento muy importante» (Celms 1931, p. 40). El enfoque fenomenológico permite entender mejor la conexión que se establece entre la conciencia y sus contenidos, preservando la distinción y separación radical entre la conciencia y las vivencias o conocimientos que esa conciencia adquiere a partir de las experiencias concretas que va teniendo, ya que la conciencia no es «una caja en la que estén contenidas las cosas mismas, ni tampoco una caja con imágenes de las cosas» (Celms 1931, p. 45), sino que se despliega como estructura constitutivamente volcada hacia las cosas y capaz de elaborar una síntesis noemática en la que participan simultáneamente un polo subjetivo y un polo objetivo, un sujeto que conoce y un objeto que es conocido, en la medida en que comparece ante el sujeto y deviene visible para él.

Sin embargo, en esas primeras obras de Husserl detecta Celms un excesivo peso de la conciencia individual, de forma que el sujeto tiene acceso directo a sus propias vivencias y contenidos de conocimiento, mientras que la existencia de la realidad exterior a la conciencia es puesta en entredicho: «lo real físico no puede ser determinado nunca absolutamente, sino siempre solo relativamente» (Celms 1931, p. 120). En el planteamiento husserliano solo la conciencia pura directamente auto-conocida y auto-captada en el momento de la epoché tiene valor absoluto, mientras que todo lo demás queda reducido a una contingencia que al letón le resulta problemática: «Husserl no convierte en absolutos los momentos del mundo real, es decir, los hechos reales» (Celms 1931, p. 140), consecuentemente todos los niveles del mundo exterior a la conciencia devienen simple facticidad inestable, quedan reducidos a cosas

2 La primera y única edición española del libro de la que se tiene constancia es T. Celms, El idealismo fenomenológico de Husserl. Madrid: Revista de Occidente, 1931. Esa edición es la que se ha consultado para elaborar el presente estudio. 
y objetos caracterizados por un mero aparecer y que podrían igualmente existir o no existir, ya que no gozan de ese estatus de 'absoluto' que sí tiene la conciencia dentro del enfoque fenomenológico. De ahí concluye nuestro autor que una «reducción a la conciencia individual tiene por ineludible consecuencia el solipsismo» (Celms 1931, p. 139).

Ese sesgo subjetivista presente en el Husserl de Ideen I es apuntado también por otros de sus discípulos, entre ellos el checo Jan Patocka, quien detecta un poso cartesiano en los planteamientos de Husserl cuando este sostiene que la conciencia, en tanto que certeza inmediata -al estilo de la idea clara y distinta de Descartes-, «debería ser tenida por una esfera autónoma de ser que además es interpretada como un ente, aunque de un tipo especial, el ente verdadero al que todo lo demás viene remitido y que se opondría, por su modo de ser, al mundo» (Ortega Rodríguez 2015, p. 262). En consonancia con esa tesis, Celms estima también que «en las Ideas de Husserl es el modo solipsístico el dominante. Solo de cuando en cuando se habla de los yos ajenos y de su darse en la experiencia introafectiva» (Celms 1931, p. 153), y esto dificulta sobremanera el acceso al conocimiento del otro y la postulación de su existencia real. Estas y otras consideraciones sobre el problema del solipsismo en el contexto de la fenomenología husserliana siguen siendo objeto de debate en la filosofía actual, aunque examinar toda esa literatura crítica trasciende el alcance de este breve trabajo. A modo de ejemplo y de contrapunto puede citarse el estudio de Natalia Carolina Petrillo publicado en Contrastes hace ya algunos años, donde se arguye que en la reducción solipsista «el otro sólo es excluido en la ficción, por lo cual permanece presupuesto, aunque no se lo tome en cuenta» (2006, p. 197), de modo que la alteridad y la existencia de los demás quedan a salvo en el esquema de Husserl. Según esta lectura, la suspensión del juicio sobre el otro no es real, sino que se trata únicamente de un artificio metodológico que sirve a la mejor comprensión de la conciencia intencional y de los procesos que esta lleva a cabo.

Volviendo sobre la crítica explicitada por Celms, diremos sumariamente que gira en torno a dos aspectos: «la posibilidad de la fenomenología de captar la realidad objetiva independientemente de la conciencia o la inmanencia del sujeto, y [...] la posibilidad de la fenomenología de romper el círculo vicioso del solipsismo» (Kule 2002, p. 12), y toda la reflexión desarrollada por el pensador letón se centra en debatir estas dos cuestiones estrechamente interrelacionadas. Según Celms, la intersubjetividad al modo en que la concibe Husserl «no se refiere a la intersubjetividad genuina, sino meramente a la intersubjetividad tal y como es dada o constituida en la propia conciencia individual» (Vegners 2011, p. 147), y deja fuera de consideración la existencia de los demás tal y como estos son en sí mismos, independientemente y más allá de la conciencia particular que los conoce, puesto que «el yo ajeno sólo existe 
para mí en el modo mediato del signo, o por medio de una intencionalidad de segundo grado» (Celms 1931, p. 157) que mantiene una distancia insalvable con la intencionalidad propia y primera que se me revela de forma inmediata en el momento de la introyección fenomenológica. El mundo real «está referido en la percepción al cuerpo de cada yo como a su punto cero de orientación» (Celms 1931, p. 161), y todos sus contenidos vienen determinados por la forma en que las cosas del mundo se dan a la conciencia. Entonces, el planteamiento husserliano aislaría a la conciencia individual al recluirla en la esfera del conocimiento de sí y de sus propias vivencias, la confina al 'enstasis' y esto da problemas a la hora de justificar ontológicamente y en sentido fuerte la existencia autónoma de otras conciencias ajenas. Si se acepta la premisa de Husserl de que «es imposible a un yo caer dentro de la intuición originaria de otro yo» (Celms 1931, p. 164), el acceso a la alteridad del otro queda cancelado y se sustituye por una versión débil de la intersubjetividad que se reduce a la captación parcial del otro -de su cuerpo, de su exterioridad- que mi conciencia lleva a cabo. ${ }^{3}$ La crítica de Celms se centra en el argumento de que, si solo puedo conocer a otros tal y como se aparecen a mi conciencia, es decir, en tanto que datum que se hace presente a su estructura intencional, resulta indemostrable la existencia de las cosas y de los otros en sí, desvinculados del conocimiento que yo tenga de ellos. Si en la fenomenología husserliana «la propia conciencia es absoluta, o lo que es lo mismo, autosuficiente, que no puede afectar ni ser afectada por nada más» (Vegners 2011, p. 151), esto conlleva que no hay interacción posible entre conciencias. Al final, prosigue Celms, este solipsismo conduce a un atolladero que se resuelve recurriendo a los argumentos metafísicos heredados de la Monadología leibniziana, pues en definitiva «la intencionalidad que se encuentra en Husserl sólo puede fundamentarse por medio de la hipótesis metafísica de una armonía preestablecida» (Celms 1931, p. 162); cada conciencia individual es una suerte de mónada cerrada y privada de contacto directo con la realidad externa a ella, la existencia de otras conciencias no se puede experimentar ni captar de forma inmediata y de ahí se sigue que el estatuto ontológico de la alteridad solo se puede garantizar a partir del postulado metafísico que afirma la existencia real de otros sujetos, por más que la conciencia individual no tenga acceso directo a ellos, y que afirma asimismo que hay un cierto orden o 'armonía' articulada a priori que posibilita que esas conciencias particulares coexistan en un mundo compartido. Pero esa presuposición tampoco proporciona una respuesta satisfactoria al problema de la intersubjetividad, sostiene Celms, en

3 Para un debate más extenso sobre el concepto de alteridad, ver O. Fernández Guerrero, «Levinas y la alteridad: cinco planos», Brocar. Cuadernos de investigación histórica, 39 (2015) pp. 423-444. 
primer lugar porque «el grado de probabilidad del principio de la armonía parece ser muy escaso» (Celms 1931, p. 178), y también porque mediante esta hipótesis solo se puede fundamentar una especie de 'solipsismo pluralista', y ni siquiera una verdadera intersubjetividad al modo en que el letón la entiende, como posibilidad de interacción de las conciencias absolutas en un mundo común que participa también de ese carácter absoluto.

No obstante, y como han señalado otros autores que han revisado los argumentos de Celms, su crítica viene condicionada por el hecho de que él es ante todo «un filósofo realista para quien la cuestión de la existencia de la realidad objetiva independiente de la conciencia o de la trascendencia es uno de los principios básicos» (Kule 2002, p. 29), y esa inquietud le lleva a formular unas exigencias que no casan bien con la propia estructura de las investigaciones fenomenológicas. De hecho, el método fenomenológico no afirma ni niega la existencia de otros, sino que estos forman parte de los contenidos del mundo puestos entre paréntesis en el momento de la epoché. «La reflexión fenomenológica es metodológicamente solipsista, pero no es solipsista per se, pues ni acepta ni niega la existencia de otros yoes» (Vegners 2011, p. 154), y de ahí se deduce que la intersubjetividad queda fuera de su alcance, en la medida en que el acceso a otros yoes trasciende los límites de lo que la conciencia puede captar de manera inmediata. La fenomenología apunta de forma general hacia la tesis de que solo conocemos directamente el mundo en su dimensión fenoménica y subjetiva; la existencia de lo nouménico, por decirlo con Kant, resulta indemostrable en estos términos, puesto que empíricamente no tenemos ninguna certeza que corrobore o refute los planos de la realidad situados más allá de los límites de la percepción. El propio Husserl y otros autores situados en esta corriente de pensamiento saben y asumen que ese solipsismo es inherente al método fenomenológico que, al suspender el juicio sobre los objetos del mundo, descubre la estructura de la conciencia en un sentido general, absoluto e independiente de los contenidos concretos que esa conciencia alberga. Celms, al contrario, tiene dificultades para aceptar estos postulados y ve ahí una limitación de la fenomenología que la invalida como método apropiado para alcanzar un conocimiento completo de la realidad, ya que deja fuera esa dimensión de mundo compartido a la que él denomina 'intersubjetividad'. El filósofo báltico concluye que la fenomenología es incompleta porque solamente permite analizar la realidad subjetiva y esta no es más que una parte del mundo, mientras que la finalidad última de la filosofía ha de ser convertirse en una ciencia universal: «la fenomenología trascendental no podría ser una filosofía universal porque no se ocupa de la realidad independiente de la conciencia» (Vegners 2012, p. 52). Celms halla en este punto un escollo insalvable en el método fenomenológico, al que reconoce empero su valor como 'idea regulativa' para la investigación 
filosófica.

\section{LA RESPUESTA DE HuSSERL: LAS MEDitACIONES CARTESIANAS}

Se sabe que el propio Husserl leyó el texto de Celms y encontró su crítica excesivamente agria, aunque reconoció también que esperaba poder dar en el futuro una justificación más fundamentada sobre «la posibilidad de un acceso puramente fenomenológico al idealismo» (Vegners 2012, p. 51). Esa justificación llega en 1929, con una serie de lecciones que Husserl dio en París y que fueron publicadas en 1931 bajo el título común de Meditaciones cartesianas. En la quinta meditación se trata específicamente el problema planteado por Celms, y Husserl admite ahí que el método fenomenológico, al reducir al individuo a su dimensión de ego trascendental absoluto, puede acabar recluyéndolo a la esfera del solus ipse, ya que «el otro en cuanto máximamente trascendente quedaría especialmente afectado por la epojé» (San Martín 1987, p. 88).

Partiendo de estas consideraciones previas, el alemán expone las distintas modalidades en que se puede captar al otro, es decir, las distintas formas o aspectos en que los alter ego se hacen presentes a mi conciencia. Se dan, por un lado, como «objetos del mundo» (Husserl 1985, p. 151). Asimismo, prosigue Husserl, experimentamos las conciencias ajenas «como gobernando psíquicamente en el cuerpo vivo natural que a cada uno le pertenece» (1985, p. 151), es decir, las captamos como entidades 'psicofísicas' compuestas de subjetividad y corporalidad, o como conciencias que animan otros cuerpos de modo análogo a como mi conciencia gobierna y regula mi propio cuerpo. ${ }^{4}$ Finalmente, experimento a los otros como sujetos que a su vez experimentan el mundo, un mundo que además me incluye a mí como contenido de esa vivencia ajena. Esto da lugar a que, en el propio acto de captar el mundo, la conciencia se percate de que ese mundo no es únicamente el resultado de una operación sintética de carácter privado, sino que es también un mundo común que se manifiesta, en una más de sus facetas, «como mundo extraño a mí, como intersubjetivo, existente para todos, accesible en sus objetos a todos» (Husserl 1985, p. 151). En nuestra vivencia y conocimiento del mundo está ya implícita la experiencia del otro, hasta el punto de afirmarse que «lo primero ajeno en sí (lo primero 'no-yo') es, pues, el otro yo» (Husserl 1985, p. 169). Se postula que, paralelamente a la subjetividad trascendental y en estrecha

4 En este sentido, la captación de la corporalidad del otro me lleva a presuponer que hay una subjetividad que yo no capto de forma directa, y que sin embargo subyace y anima el movimiento de ese cuerpo ajeno al mío. Para una discusión más detallada sobre esta cuestión, $c f$. $\mathrm{D}$. D'Angelo, «The foundations of alterity. Husserl on referencing and indicating», Investigaciones fenomenológicas 10 (2013) pp. 53-71. 
conexión con ella, surge una intersubjetividad trascendental que funciona como 'comunidad de mónadas' y que «constituye intersubjetivamente el mundo objetivo» (Husserl 1985, p. 169). De ahí se sigue que el mundo nunca se me presenta únicamente como mi mundo, sino que «en mis perspectivas están implicados otros sujetos; con lo cual que tenemos que la subjetividad constituyente del mundo no soy sólo yo sino que necesariamente tenemos que ser nosotros» (San Martín 1987, p. 90). En los límites de la experiencia del sujeto trascendental se constata que hay «una única comunidad total, que me comprende también a mí mismo» (Husserl 1985, p. 208); cada ser humano concreto percibe su pertenencia a una comunidad compartida, existe en un horizonte social en el que la subjetividad trascendental se encuentra con otras subjetividades similares y las reconoce por analogía.

Al abrir esta vía de reflexión, Husserl encaja la cuestión de la intersubjetividad en su esquema filosófico y muestra cómo la existencia de otros puede fundamentarse partiendo de las premisas de la reducción fenomenológica. No obstante, según señala Javier San Martín, muchos han sido los fenomenólogos que han considerado que Husserl nunca superó el solipsismo, entre ellos Schütz o Theunissen (San Martín 1987, p. 91), además del propio Celms, del que nos ocupamos aquí. Sea como fuere, es evidente que el debate filosófico sobre el problema del solipsismo en la fenomenología ha tenido una relevancia creciente en el pensamiento contemporáneo. Dentro de esas discusiones, y más allá del acuerdo o desacuerdo que puedan generar los planteamientos de Celms en su crítica general a Husserl, es evidente que el filósofo letón comprendió e identificó muy tempranamente algunas de las dificultades presentes en el método fenomenológico, y en ese sentido fue precursor de una línea crítica que ha dejado huella en la filosofía continental del último siglo. Por esta razón, es de justicia reconocer las aportaciones de Celms al debate sobre el pensamiento husserliano y situarlo en la estela de una corriente crítica de la fenomenología cuyo cauce discurre por todo el siglo XX y llega hasta nuestros días.

\section{REFERENCIAS BIBLIOGRÁFICAS}

BUCENIECE, E. 2003: «Teodors Celms, Kurt Stavenhagen and Phenomenology in Latvia», Analecta Husserliana 80: 312-316.

CELMS, T. 1931: El idealismo fenomenológico de Husserl, tr. J. Gaos. Madrid: Revista de Occidente.

D'ANGELO, D. 2013: «The foundations of alterity. Husserl on referencing and indicating», Investigaciones fenomenológicas 10: 53-71.

FERNÁNDEZ GUERRERO, O. 2015: «Levinas y la alteridad: cinco planos», Brocar. Cuadernos de investigación histórica 39: 423-444. 
HUSSERL, E. 1985: Meditaciones cartesianas, tr. J. Gaos y M. García-Baró. Madrid: FCE.

KULE, M. 2002: Phenomenology and Culture. Riga: University of Latvia.

ORTEGA MARTÍNEZ, I. 2015: «La crítica de Patocka a Husserl: subjetividad trascendental frente al mundo como trascendental», Investigaciones fenomenológicas 5: 255-285.

PETRILLO, N. C. 2006: «Consideraciones en torno a la reducción solipsista», Contrastes. Revista Internacional de filosofía XII: 185-205.

SAN MARTÍN, J. 1987: La fenomenología de Husserl como utopía de la razón. Barcelona: Anthropos.

VEGNERS, U. 2012: «Theodore Celms' Critique of Husserl's Transcendental Phenomenology», Quaestiones Disputatae 3(1): 48-64.

VEGNERS, U. 2011: «Theodore Celms' Critique of Edmund Husserl's Phenomenology in the context of the problem of solipsism», Humanities and Social Sciences Latvia 19: 143-157.

Olaya Fernández Guerrero es profesora de Filosofía en UNED La Rioja.

Líneas de Investigación:

Filosofía contemporánea, Estudios de género

Publicaciones recientes:

(2016): «Cuerpo vivido e (in)visibilidad en Merleau-Ponty», Horizontes filosóficos. Revista de Filosofía, Humanidades y Ciencias Sociales 6: 37-51.

(2016): «Diferencia y heterodesignación. Críticas desde la periferia», en Aragüés, J. M., Capmartin, T., Mékouar-Hertzberg, N. y Saldaña, A. (eds.) y Paz, F. (coord.), La diferencia en cuestión/La cuestión de la diferencia. La différence en question/ La question de la différence, Zaragoza: Mira Editores, pp. 379-392.

Correo electrónico: olayafg@yahoo.es 